\title{
Analysis and Comparative Study of Catheter Drainage or Needle Aspiration in Management of Liver Abscess
}

Dr. Aakash G. Rathod ${ }^{1 *}$, Dr. Sanket Katara ${ }^{1}$, Dr. Asim Mansuri ${ }^{2}$, Dr. Kuldeep Vanvi ${ }^{2}$, Dr. Aimanhusen M. Payala ${ }^{2}$, Dr. Aarsh Panchal ${ }^{2}$, Dr. Jaykumar Patel ${ }^{2}$

\footnotetext{
${ }^{1}$ MS, Assistant Professor, Department of General Surgery, Sheth Lallubhai Gordhandas Municipal General Hospital, LG Hospital Rd, Balvatika, Maninagar, Ahmedabad, Gujarat 380008, India

${ }^{2}$ MBBS, Resident Doctor Ms, Department Of General Surgery, Sheth Lallubhai Gordhandas Municipal General Hospital, Affiliated To AMC Met Medical College, Maninagar, Ahmedabad, India
}

DOI: $10.36347 /$ sjams.2022.v10i01.012

| Received: 11.12.2021 | Accepted: 10.01.2022 | Published: 19.01.2022

*Corresponding author: Dr. Aakash G. Rathod

MS, Assistant Professor, Department of General Surgery, Sheth Lallubhai Gordhandas Municipal General Hospital, LG Hospital Rd, Balvatika, Maninagar, Ahmedabad, Gujarat 380008, India

Abstract

Original Research Article

Background: Liver abscess is common cause of illness in developing nations. Even with the advance investigation like ultrasonography, the diagnosis is still delayed due to the nonconclusive manifestations of disease and for that reason the tentative diagnosis is important. Methods: 60 patients were selected from L.G. HOSPITAL, Ahmedabad. Study was conducted during the period from June 2020 to October 2021. Results: Percutaneous catheter drainage is having less compliance compared to needle aspiration. Repeated procedures needed to improve the success of percutaneous needle aspiration $56.66 \%$ of the subjects presented with complications in USG guided needle aspiration group whereas only $26.66 \%$ of people presented with complications in USG guided pigtail catheter drainage group. The most common complication in needle aspiration group was re-accumulation leading to repeated aspiration $40 \%$. The of the most common complication in catheter drainage group is blockage of drain due to thick pus $10 \%$. Conclusions: USG guided catheter drainage and USG guided needle aspiration are equally efficient in the management of significant sized liver abscesses.

Keywords: Amoebic Liver Abscess; pigtail catheter; liver; Ultrasonography; Conservative Management; Postprocedure complications; Morbidity.

Copyright $\odot 2022$ The Author(s): This is an open-access article distributed under the terms of the Creative Commons Attribution 4.0 International License (CC BY-NC 4.0) which permits unrestricted use, distribution, and reproduction in any medium for non-commercial use provided the original author and source are credited.

\section{INTRODUCTION}

Liver abscess as pyogenic and amoebic are one of the important causes of morbidity and mortality in developing countries [1].

Even with the advent of good diagnostic investigation like USG, the diagnosis is still delayed because of the nonspecific manifestations of illness and therefore the suspicion of the diagnosis is important. During the last few years, the advances of newer radiological techniques namely computed tomography (CT) and ultrasonography (USG) has not only prescribed tools for precise localization of these abscess. Percutaneous therapeutic procedures have been surpassing compared with open surgical drainage (SD) [2]. This study aims to compare the therapeutic efficacy and safety of 'Percutaneous continuous catheter drainage' against to 'Percutaneous needle aspiration' in management for liver abscesses.

\section{MeTHODS \\ Source of data}

In this comparative research, 60 patients were selected from L.G. HOSPITAL, Ahmedabad. Study was performed during the period from June 2020 to October 2021.

\section{Methods of collection of data}

The study was a prospective study of diagnosed cases of liver abscess from June 2010 to October 2021. A total 60 patients were added in the study and patients were randomly divided into 2 groups. Group A: Ultrasonography guided percutaneous needle aspiration. Group B: Ultrasonography guided indwelling catheter drainage group. Groups were examined to find aetiopathogenesis and better therapy technique. The patients included in the study were diagnosed cases of liver abscess; admitted through surgical outdoor patient department or emergency

Citation: Dr. Aakash G. Rathod, Dr. Sanket Katara, Dr. Asim Mansuri, Dr. Kuldeep Vanvi, Dr. Aimanhusen M. Payala, Dr. Aarsh Panchal, Dr. Jaykumar Patel. Analysis and Comparative Study of Catheter Drainage or Needle Aspiration in Management of Liver Abscess. Sch J App Med Sci, 2022 Jan 10(1): 79-81. 
department in the indoor wards of L.G Hospital from June 2018 to October 2020.A total of 60 patients with liver abscess were signed up and randomly divided into 2 groups. All patients had ultrasound done at the time of admission All patients were given Inj. Ceftriaxone $1 \mathrm{gm}$ IV 12 hourly, Inj. Metronidazole 400mg IV 8 hourly and vit K. Patients randomised into two groups: Group A (total patients 30) treated with anti-amoebic drugs with ultrasonography guided needle aspiration on the day of admission. Group B (total 30 patients) treated with anti-amoebic drugs with percutaneous indwelling catheter insertion. Patients were examined daily for body temperature, pain and tenderness, laboratory and radiological workup was done as and when required. Cure was defined as improvement clinically with recovery from fever, and local signs, symptoms, decrease in WHITE BLOOD CELL count and followup USG showed reduction and no evidence of relapses.

\section{RESULTS}

The study was done at L.G hospital, Ahmedabad during period from July 2020 to October 2021. 60 cases of liver abscesses were studied and they were randomised into two groups as Group A (total patients 20) treated with anti-amoebic drugs plus needle aspiration and Group B (total patients 10) treated with anti-amoebic Drugs with percutaneous catheter insertion .All patients were given anti-amoebic drugs and observed for $48 \mathrm{hrs}$. USG was done on Day5 \& 15 Other findings included in the study are summarised as By day 15, USG showed decreased size of abscess cavity in all patients but reduction in cavity size was more $(92 \%)$ in group B as compared to $(75 \%)$ in group A . 60 cases of liver abscess were undertaken in the present study. A detailed evaluation and analysis of the comparison between ultrasound guided needle aspiration and usg guided catheter drainage was undertaken keeping in mind the aims and objectives in this study. The following conclusions were derived. Both, procedures are very safe with minimal complications if performed carefully.

Present study has been taken up with the aim to compare advantages and disadvantages of USG guided percutaneous needle aspiration to USG guided pigtail catheter drainage. Pigtail catheter drainage is better compared to percutaneous needle aspiration. Frequent aspiration needed to improve the success of percutaneous needle aspiration. Average duration of stay in catheter drainage group (06 days) was less compared to needle aspiration group (11 days).USG guided pigtail catheter drainage and USG guided percutaneous needle aspiration are equally effective in the management of large liver abscesses. Percutaneous catheter drainage better in terms of Quicker compared to repeated needle aspiration as Less duration of hospital stay, Less complications, complete resolution of abscess cavity.

\section{DISCUSSION}

Total 60 patients of liver abscess were involved in the study. Patients randomly separated into two groups. group A (total no patients 30) treated with amoebicidal drugs plus ultrasound guided needle aspiration \& group B (total no patients 30 ) treated with amoebicidal drugs with pigtail catheter insertion [3].

Follow up after starting of therapy let drop to normal value of body temperature in all patients within 07 days in both groups abdominal pain resolved in $85 \%$ of patients within 5 days Tenderness of liver resolved in $90 \%$ patients in both groups. All patients were relieved from pain, fever and tenderness on day 8. Laboratory parameters improved in all patients on day10, As day 15 onwards, liver abscess cavity size decreased in usg finding but, residual abscess size was reduced better in group B as compared to group A. In Group A cases having liver abscess size of 5 to $10 \mathrm{~cm}$ reduced after procedure up to $75-90 \%$ in size by 10 days compared to Group B having reduced after procedure up to $50-95 \%$ in size by 10days of follow-up ultrasound.

In our study males are dominantly affected compared to female with a average age 31 to 40 years old [4]. Most common complaint of patients are as Abdominal pain $>$ fever $>$ anorexia $>$ weight loss $>$ diarrhoea $>$ Jaundice [5]. RHC tenderness was the most consistent sign in all 55 cases $(91.66 \%)$. Fever was present in $75 \%$ cases, hepatomegaly in $23 \%$ cases, icterus in $16.66 \%$, pallor in $13.33 \%$, pedal oedema in $30 \%$ cases. Anaemia was found in $30 \%$ cases, Leucocytosis present in $84 \%$ cases, alteration in Alkaline phosphatase in 55\%, altered Prothrombin time in $50 \%$, hyperbilirubinemia in $30 \%$ \& hypoalbuminemia in $60 \%$ cases. Abnormalities in chest Xray was found as raised dome of diaphragm $>$ right sided pleural effusion $>$ right sided pneumonitis [6]. In ultrasound examination, liver abscess found predominantly involving right lobe of liver compared to left lobe of liver. Complications in management protocol of liver abscess are less in indwelling pigtail catheter drainage group as compared to ultrasonography guided needle aspiration group [7].

\section{REFERENCES}

1. Wells, C. D., \& Arguedas, M. (2004). Amebic liver abscess. Southern medical journal, 97(7), 673-683.

2. Politano, A. D., Hranjec, T., Rosenberger, L. H., Sawyer, R. G., \& Tache Leon, C. A. (2011). Differences in morbidity and mortality with percutaneous versus open surgical drainage of postoperative intra-abdominal infections: a review of 686 cases. The American surgeon, 77(7), 862867.

3. Hatchuel, W. (1975). Tinidazole for the treatment of amoebic liver abscess. South African Medical Journal, 49(45), 1879-1881.

4. Congly, S. E., Shaheen, A. A. M., Meddings, L., 
Aakash G. Rathod et al; Sch J App Med Sci, Jan, 2022; 10(1): 79-81

Kaplan, G. G., \& Myers, R. P. (2011). Amoebic liver abscess in USA: a population-based study of incidence, temporal trends and mortality. Liver International, 31(8), 1191-1198.

5. Kumar, S. K., Uppal, B., Kant, K., Aggarwal, P., Ram, D., \& Panda, P. S. (2017). Amoebic Liver Abscess: A Complete Overview in Tertiary Care Centre.

6. Ramachandran, S., Jayawardena, D. L. N., \&
Perumal, J. R. A. (1971). Radiological changes in hepatic amoebiasis. Postgraduate medical journal, 47(551), 615-621.

7. Nigam, B., Srivastava, M., Nigam, S., \& Chauhan, C. (2019). Comparative Study of Percutaneous Needle Aspiration Versus Catheter Drainage In Treating Hepatic Abscess. Journal of Evolution of Medical and Dental Sciences, 8(9), 572-580. 